ARTICLE

https://doi.org/10.1038/s41467-019-13424-7

\title{
Polar surface structure of oxide nanocrystals revealed with solid-state NMR spectroscopy
}

\author{
Junchao Chen (10 1,6, Xin-Ping Wu (10) 2,3,6*, Michael A. Hope (1) 4,6, Kun Qian', David M. Halat (1) 4, Tao Liu4, \\ Yuhong Li', Li Shen ${ }^{1}$, Xiaokang Ke ${ }^{1}$, Yujie Wen (1) ${ }^{1}$, Jia-Huan Du (1) ${ }^{1}$, Pieter C.M.M. Magusin ${ }^{4}$, Subhradip Paul (1) ${ }^{5}$, \\ Weiping Ding ${ }^{1}$, Xue-Qing Gong ${ }^{2}$, Clare P. Grey ${ }^{4 \star} \&$ Luming Peng (i) ${ }^{1 \star}$
}

Compared to nanomaterials exposing nonpolar facets, polar-faceted nanocrystals often exhibit unexpected and interesting properties. The electrostatic instability arising from the intrinsic dipole moments of polar facets, however, leads to different surface configurations in many cases, making it challenging to extract detailed structural information and develop structure-property relations. The widely used electron microscopy techniques are limited because the volumes sampled may not be representative, and they provide little chemical bonding information with low contrast of light elements. With ceria nanocubes exposing (100) facets as an example, here we show that the polar surface structure of oxide nanocrystals can be investigated by applying ${ }^{17} \mathrm{O}$ and ${ }^{1} \mathrm{H}$ solid-state NMR spectroscopy and dynamic nuclear polarization, combined with DFT calculations. Both $\mathrm{CeO}_{4}$-termination reconstructions and hydroxyls are present for surface polarity compensation and their concentrations can be quantified. These results open up new possibilities for investigating the structure and properties of oxide nanostructures with polar facets.

\footnotetext{
${ }^{1}$ Key Laboratory of Mesoscopic Chemistry of MOE and Collaborative Innovation Center of Chemistry for Life Sciences, School of Chemistry and Chemical Engineering, Nanjing University, 163 Xianlin Road, Nanjing 210023, China. ${ }^{2}$ Key Laboratory for Advanced Materials, Centre for Computational Chemistry and Research Institute of Industrial Catalysis, East China University of Science and Technology, 130 Meilong Road, Shanghai 200237, China. ${ }^{3}$ Department of Chemistry, Chemical Theory Center, and Supercomputing Institute, University of Minnesota, 207 Pleasant Street SE, Minneapolis, MN 55455-0431, USA. ${ }^{4}$ Department of Chemistry, University of Cambridge, Lensfield Road, Cambridge CB2 1EW, UK. ${ }^{5}$ DNP MAS NMR Facility, Sir Peter Mansfield Magnetic Resonance Centre, University of Nottingham, Nottingham NG7 2RD, UK. ${ }^{6}$ These authors contributed equally: Junchao Chen, Xin-Ping Wu, Michael A. Hope. *email: xpwu@ecust.edu.cn; cpg27@cam.ac.uk; luming@nju.edu.cn
} 
P olar surfaces, which have a permanent dipole moment perpendicular to the surface, are of great importance in both physical and chemical applications ${ }^{1-4}$. Due to the very large energies of uncompensated surfaces, polarity compensation is required, generating different and complex surface configurations for these facets. Therefore, it is extremely difficult to understand the atomic-scale structure of polar surfaces, which is essential in order to design related nanomaterials for a targeted property $^{5-8}$. By applying electron microscopy and computational modelling, a variety of polarity compensation mechanisms have been proposed, including ordered surface reconstructions ${ }^{9}$, surface disorder ${ }^{10}$, adsorption of environmental gas molecules ${ }^{11}$, surface metal layers deposition ${ }^{12}$, and subsurface oxygen vacancies $^{13}$. Despite the many advantages of microscopy techniques, they are limited to the visualization of a small fraction of the sample which may not yield reliable quantitative information about the whole sample, and are typically performed at high vacuum conditions that may alter the surface environment ${ }^{14}$. Furthermore, light elements, such as hydrogen and oxygen which are of key importance for many materials, are difficult to probe with such techniques ${ }^{15}$. Although significant developments have been made in environmental electron microscopy, which allows materials to be investigated under adjustable pressure conditions and in variable gaseous environments ${ }^{16-18}$, the other disadvantages remain and complementary methods are required.

Solid-state NMR spectroscopy is a powerful method which can provide rich local structural information for solids ${ }^{19-26}$, complementary to the information obtainable from diffraction ${ }^{27}$ and microscopy techniques. Recently, ${ }^{17} \mathrm{O}$ solid-state NMR spectroscopy has been developed as a new approach for determining the surface structure of oxide nanomaterials, with help from surfaceselective labeling and DFT calculations. Oxygen ions in different layers of ceria nanostructures ${ }^{28}$ and at different facets of anatase titania nanocrystals ${ }^{29}$ can be distinguished according to the NMR shifts. However, only non-polar facets were studied previously and no attempt was made to investigate the more challenging oxide nanostructures with polar facets. Furthermore, quantification of different surface species was not possible using exclusively ${ }^{17} \mathrm{O} \mathrm{NMR}$, due to the quadrupolar nature of ${ }^{17} \mathrm{O}$ and the potentially non-uniform isotopic labeling procedure.

Ceria nanocubes expose (100) facets, which show exceptional properties as both the catalytically active plane and the support facet; this is a relatively simple polar surface, making ceria nanocubes an ideal model ${ }^{30-33}$. Using the example of ceria nanocubes, we introduce a strategy of qualitative ${ }^{17} \mathrm{O}$ and quantitative ${ }^{1} \mathrm{H}$ solid-state NMR spectroscopy combined with DFT calculations to characterize oxide nanocrystals with polar facets. We thereby quantitatively determine detailed polar surface structural information, specifically the presence and concentration of reconstructed $\mathrm{Ce}$ terminated structures $\left(\mathrm{CeO}_{4}-\mathrm{t}\right)$ and hydroxyl groups.

\section{Results}

Morphology of the ceria nanocubes. Ceria nanocubes were hydrothermally synthesized with $\mathrm{Ce}\left(\mathrm{NO}_{3}\right)_{3} \cdot 6 \mathrm{H}_{2} \mathrm{O}$ and $\mathrm{NaOH}$ (see methods). The X-ray diffraction (XRD) data (Supplementary Fig. 1) confirms the formation of ceria with a fluorite structure (JCPDS No. 34-0394). High-resolution transmission electron microscopy (HRTEM) images show that the samples adopt a cubic morphology with sizes of 18 to $40 \mathrm{~nm}$, dominated by (100) polar surfaces before and after ${ }^{17} \mathrm{O}$ enrichment (Supplementary Fig. 2). Inductively coupled plasma mass spectrometry (ICP-MS), elemental analysis and X-ray photoelectron spectroscopy (XPS) data show that there are no detectable $\mathrm{Na}^{+}$or $\mathrm{NO}_{3}{ }^{-}$impurities (Supplementary Fig. 3 and Supplementary Table 1). In addition,

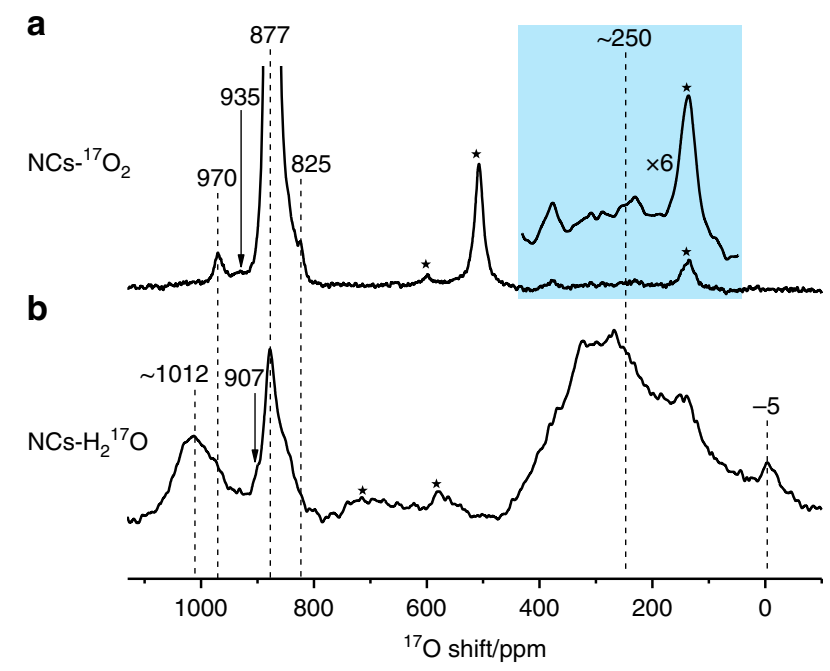

Fig. $1{ }^{17} \mathrm{O}$ Solid-State NMR spectra of ceria nanocubes. The ${ }^{17} \mathrm{O} N M R$ measurements were performed at a spinning speed of $20 \mathrm{kHz}$ for $\mathrm{NCs}-{ }^{17} \mathrm{O}_{2}$ (a) and $16 \mathrm{kHz}$ for $\mathrm{NCs}-\mathrm{H}_{2}{ }^{17} \mathrm{O}$ (b). A rotor synchronized Hahn-echo pulse sequence $\left(\pi / 6-\tau-\pi / 3-\tau\right.$-acquisition) with ${ }^{1} \mathrm{H}$ decoupling and a 0.5 s recycle delay was used. Stars denote spinning sidebands. In order to show the peaks due to $\mathrm{OH}$ better, a line broadening of $600 \mathrm{~Hz}$ is applied for the enlarged spectrum shown in light blue region.

the concentration of oxygen vacancies at the surface is only $1.0 \%$ according to analysis of Raman spectroscopy data and, therefore, their influences are not considered further (Supplementary Fig. 4 and Supplementary Note 1).

NMR spectra of the ceria nanocrystals. The ${ }^{17} \mathrm{O}$ solid-state NMR spectra of ceria nanocubes enriched with ${ }^{17} \mathrm{O}_{2}$ at $523 \mathrm{~K}$ (NCs- ${ }^{17} \mathrm{O}_{2}$ ) and $\mathrm{H}_{2}{ }^{17} \mathrm{O}$ at $373 \mathrm{~K}\left(\mathrm{NCs}-\mathrm{H}_{2}{ }^{17} \mathrm{O}\right)$ are shown in Fig. 1. The ${ }^{17} \mathrm{O}$ NMR spectrum of $\mathrm{NCs}^{-17} \mathrm{O}_{2}$ is dominated by the peak at $877 \mathrm{ppm}$ (see the untruncated spectrum in Supplementary Fig. 5) due to the $\mathrm{OCe}_{4}$ environment in the bulk of the ceria nanocubes, but other signals can also be observed at 970, 935, and $825 \mathrm{ppm} .{ }^{17} \mathrm{O}$ NMR signals for ceria samples with (111) facets have previously been observed at 1040, 920, and $825 \mathrm{ppm}$ due to oxygen ions in the first, second, and third (sub-)surface layers respectively ${ }^{28}$; the shoulder resonance at $825 \mathrm{ppm}$ in the NCs${ }^{17} \mathrm{O}_{2}$ spectrum is therefore most likely due to a deeper sub-surface layer while the signals at 970 and 935 ppm, which have not previously been observed, may be tentatively assigned to the oxygen ions at the (100) surface.

For the spectrum of $\mathrm{NCs}-\mathrm{H}_{2}{ }^{17} \mathrm{O}$, in addition to the bulk signal with a maximum at $877 \mathrm{ppm}$, two broad peaks centered at approximately 250 and $1012 \mathrm{ppm}$ can be observed. The former is most likely to be related to surface hydroxyl groups $(\mathrm{Ce}-\mathrm{OH})^{29,34}$, and on closer inspection can also just be distinguished for NCs${ }^{17} \mathrm{O}_{2}$. The latter can again, based on its high frequency compared to the bulk resonance, be attributed to under-coordinated surface oxygen species. Surface-selective isotopic labeling is achieved by exposing the samples to ${ }^{17} \mathrm{O}_{2}$ gas or to $\mathrm{H}_{2}{ }^{17} \mathrm{O}$ vapor at relatively low temperatures, although there are differences between the spectra that will be discussed later.

A possible explanation for the higher frequency signal in the spectrum of $\mathrm{NCs}-\mathrm{H}_{2}{ }^{17} \mathrm{O}$ is the formation of some degree of the thermodynamic (111) surface, given that the first surface layer in this case has been observed at 1040 ppm. However, the HRTEM images show little evidence for (111) facets (Supplementary Fig. 2), and after re-enriching $\mathrm{NCs}-\mathrm{H}_{2}{ }^{17} \mathrm{O}$ with ${ }^{17} \mathrm{O}_{2}$ gas, the surface signals are identical to those of $\mathrm{NCs}^{-17} \mathrm{O}_{2}$ and do not 
a

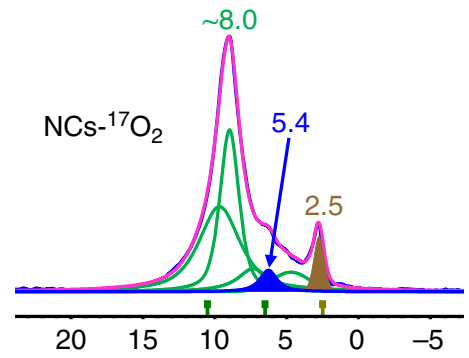

b

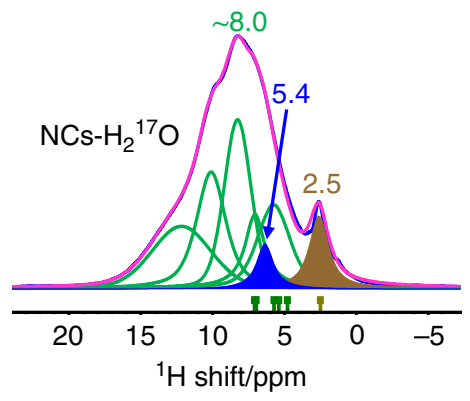

C

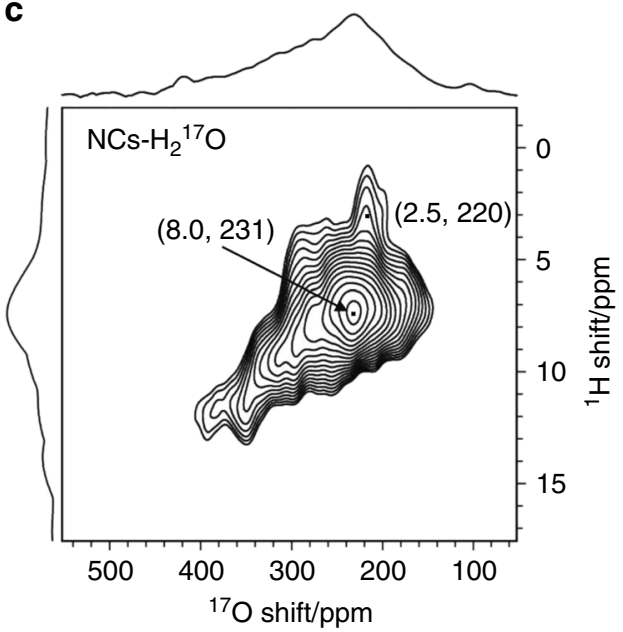

Fig. $2{ }^{1} \mathrm{H}$ Solid-State NMR spectra and ${ }^{1} \mathrm{H} \rightarrow{ }^{17} \mathrm{O}$ HETCOR NMR of ceria nanocubes. The ${ }^{1} \mathrm{H}$ NMR measurements for $\mathrm{NCs}^{-17} \mathrm{O}_{2}(\mathbf{a})$ and $\mathrm{NCs}^{-} \mathrm{H}_{2}{ }^{17} \mathrm{O}$ (b) were performed at a spinning speed of $12 \mathrm{kHz}$ using a rotor synchronized Hahn-echo pulse sequence $(\pi / 2-\tau-\pi-\tau$-acquisition) with a recycle delay of $2.0 \mathrm{~s}$. Deconvolution of ${ }^{1} \mathrm{H}$ spectra and the summarized ${ }^{1} \mathrm{H}$ chemical shifts (obtained from DFT calculations, see below) are also shown. Background signals from the cap, rotor and probe etc. are removed by subtracting the spectra of an empty rotor obtained at the same condition from the initial spectrum. c The ${ }^{1} \mathrm{H} \rightarrow{ }^{17} \mathrm{O}$ HETCOR spectrum of $\mathrm{NCs}-\mathrm{H}_{2}{ }^{17} \mathrm{O}$, recorded at a MAS rate of $14 \mathrm{kHz}$ with a recycle delay of $2 \mathrm{~s}$ and a contact time of $0.5 \mathrm{~ms}$.

exhibit signals associated with (111) surfaces (Supplementary Fig. 6). This suggests that the high frequency signal is related to the (100) surface itself and the $\mathrm{H}_{2}{ }^{17} \mathrm{O}$ enrichment.

To investigate the presence of hydroxyl groups or molecularly adsorbed $\mathrm{H}_{2} \mathrm{O}$ on the ceria surface, quantitative ${ }^{1} \mathrm{H}$ NMR was performed. ${ }^{1} \mathrm{H}$ chemical shifts are sensitive to hydrogen bonding 35,36 and the lineshapes can be affected by the distribution of hydrogen bond distances; in particular, stronger hydrogen bonding results in higher frequency ${ }^{1} \mathrm{H}$ NMR signals ${ }^{37}$. The spectrum of $\mathrm{NCs}^{-17} \mathrm{O}_{2}$ in Fig. 2a shows a broad resonance between 2-16 ppm (the sum of the green deconvoluted Lorentzian functions), along with a shoulder at $5.4 \mathrm{ppm}$ (blue signal), and a relatively sharp peak at $2.5 \mathrm{ppm}$ (brown signal); a summary of these deconvoluted signals is presented in Supplementary Table 2 . The signal at $5.4 \mathrm{ppm}$ is most likely due to molecularly adsorbed water molecules and the $2.5 \mathrm{ppm}$ signal can be assigned to terminal hydroxyl species $\left(-\mathrm{OH}_{\mathrm{T}}\right)^{38}$; the remaining intensity is then assigned to bridging hydroxyl groups $\left(-\mathrm{OH}_{\mathrm{B}}\right)$ with a distribution of environments and degrees of hydrogen bonding. A similar ${ }^{1} \mathrm{H}$ NMR spectrum was observed for NCs$\mathrm{H}_{2}{ }^{17} \mathrm{O}$ (Fig. 2b), but with a broader signal centered around 8 ppm, corresponding to bridging hydroxyl groups with an even greater distribution of environments and hydrogen bonding. Quantitative analysis of the integrated ${ }^{1} \mathrm{H}$ intensities, combined with the specific surface areas as measured from the BET isotherms, yields adsorbed water contents for $\mathrm{NCs}^{-17} \mathrm{O}_{2}$ and NCs- $\mathrm{H}_{2}{ }^{17} \mathrm{O}$ of 2.6 and $3.7 \mathrm{H}_{2} \mathrm{O}$ molecules per surface unit (59.3 $\AA^{2}$ ), respectively. Of these, $0.2 \mathrm{H}_{2} \mathrm{O}$ molecules are molecularly adsorbed for both $\mathrm{NCs}^{17} \mathrm{O}_{2}$ and $\mathrm{NCs}-\mathrm{H}_{2}{ }^{17} \mathrm{O}$, while the rest are dissociatively adsorbed to form hydroxyl groups (see Supplementary Fig. 7 and Supplementary Table 3). The quantitative ${ }^{1} \mathrm{H}$ NMR spectroscopy indicates that there are similar concentrations of hydroxyl groups on both $\mathrm{NCs}-{ }^{17} \mathrm{O}_{2}$ and $\mathrm{NCs}-\mathrm{H}_{2}{ }^{17} \mathrm{O}$, however the intensity of signals from hydroxyl groups in the ${ }^{17} \mathrm{O}$ NMR spectrum of the former is much lower. This is ascribed to unenrichment of the oxygen atoms of the hydroxyl groups for NCs $-{ }^{17} \mathrm{O}_{2}$ by natural abundance water, which is not completely dehydrated at the relatively low temperature of $523 \mathrm{~K}$. In contrast, the surface water of $\mathrm{NCs}-\mathrm{H}_{2}{ }^{17} \mathrm{O}$ is replaced by $\mathrm{H}_{2}{ }^{17} \mathrm{O}$, so the same unenrichment does not occur.

The ${ }^{1} \mathrm{H} \rightarrow{ }^{17} \mathrm{O}$ HETCOR NMR spectrum of $\mathrm{NCs}-\mathrm{H}_{2}{ }^{17} \mathrm{O}$ (Fig. 2c) shows correlations between the ${ }^{17} \mathrm{O}$ signals at around $250 \mathrm{ppm}$ with the ${ }^{1} \mathrm{H}$ signals due to hydroxyl groups, confirming the assignment of the ${ }^{17} \mathrm{O}$ NMR spectra. Furthermore, hydroxyl sites with higher ${ }^{17} \mathrm{O}$ shifts are associated with higher ${ }^{1} \mathrm{H}$ shifts, and thus a stronger acidity (although stronger hydrogen bonding can also result in larger shifts ${ }^{39}$. The conclusion that bridging hydroxyl groups are more acidic than terminal hydroxyls is in agreement with previous reports in zeolites ${ }^{39}$. Since the ${ }^{17} \mathrm{O}$ NMR shift range is much wider than for ${ }^{1} \mathrm{H}$ NMR shifts, ${ }^{17} \mathrm{O}$ NMR spectroscopy may provide an alternative and more sensitive probe of the acidity and acid-catalysis reactivity for oxide nanomaterials. However, ${ }^{17} \mathrm{O}$ NMR experiments often require spectra acquired at multiple magnetic fields, preferably higher fields, or with high resolution techniques (e.g., MQMAS ${ }^{40}$ ), in order to decrease the linewidths arising from quadrupolar interactions.

Spectral Assignments from DFT Calculations. DFT calculations have previously proved successful in aiding spectral assignment for surface oxygen ions in oxide nanostructures 28,29 . The differences between the calculated and experimental results are generally around or less than $10 \mathrm{ppm}^{28}$, allowing reliable spectral assignment. An oxygen terminated (O-t) model of ceria (100) surface was previously investigated for DFT calculations ${ }^{28}$ (Fig. 3a), however, the calculated ${ }^{17} \mathrm{O}$ NMR parameters (Supplementary Figs. 8-10 and Supplementary Table 4) are not in agreement with our NMR observations, i.e., no surface species in the calculations are associated with resonant frequencies at 970 , 935 or $1012 \mathrm{ppm}$ and the calculated signal for the $1^{\text {st }}$ layer twocoordinate oxygen ion $\left(\mathrm{O}_{2} \mathrm{C}\right)$, with a high frequency chemical shift (1117 ppm), is not observed in the experimental spectrum.

As seen from the ${ }^{1} \mathrm{H}$ and ${ }^{17} \mathrm{O}$ NMR spectra, a significant number of hydroxyl groups are present at the surface, which must be considered. A previous computational study reported that dissociative adsorption of water is much more favorable than the molecular adsorption of water on the (100) O-t surface ${ }^{41}$; accordingly, DFT calculations were performed on O-t models with $1,2,3$ and 4 dissociatively adsorbed $\mathrm{H}_{2} \mathrm{O}$ molecules per O-t 


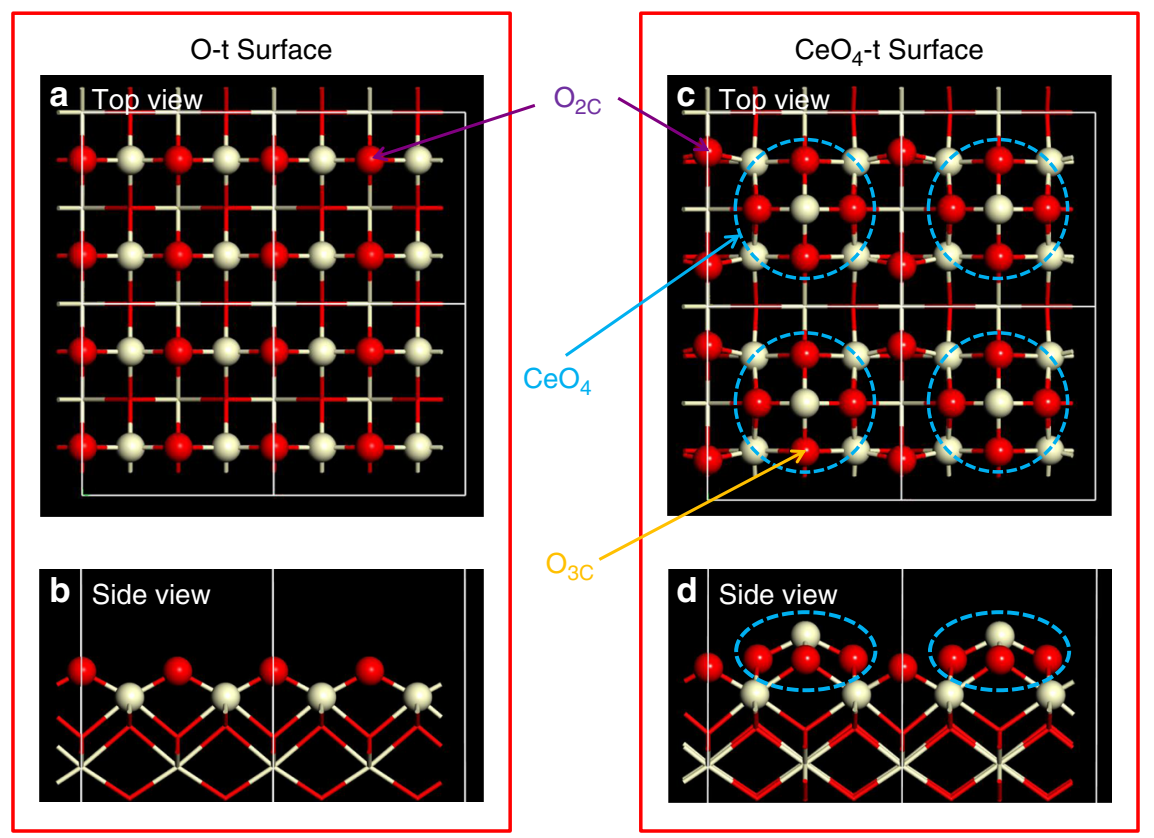

Fig. 3 Structure of $\mathrm{O}-\mathrm{t}$ and $\mathrm{CeO}_{4}$-t surface. Surface oxygen ions are represented as red balls and cerium ions as off-white, in the top and side views of ceria (100) facets with an O-t surface $(\mathbf{a}, \mathbf{b})$ and a $\mathrm{CeO}_{4}$-t surface $(\mathbf{c}, \mathbf{d})$. The top views $(\mathbf{a}, \mathbf{c})$ each show four surface units (each surface unit is $7.7 \AA \times 7.7 \AA=$ $59.3 \AA^{2}$ ), delimited by white boxes. Each O-t surface unit includes four $\mathrm{O}_{2} \mathrm{C}$ ions, while each $\mathrm{CeO}_{4}$-t surface unit contains two $\mathrm{O}_{2} \mathrm{C}$ ions and one $\mathrm{CeO} 4$ reconstruction (blue dashed circle), with four three-coordinated oxygen ions $\left(\mathrm{O}_{3} \mathrm{C}\right)$.

surface unit (Supplementary Figs. 11-23 and Supplementary Tables 5-8). On reaction with water, the under-coordinated $\mathrm{O}_{2 \mathrm{C}}$ sites with high chemical shifts are protonated to form hydroxyl groups with calculated shifts of 191-360 ppm, as observed in the experimental ${ }^{17} \mathrm{O}$ NMR spectra; four dissociated $\mathrm{H}_{2} \mathrm{O}$ molecules per O-t surface unit are required to protonate all the $\mathrm{O}_{2 \mathrm{C}}$ sites (monolayer hydroxylation, see Supplementary Fig. 20). However, there are no calculated resonances at 970,935 or $\sim 1012 \mathrm{ppm}$; this suggests that the structure of polar (100) facets in ceria nanocubes is more complicated than the simple O-t model.

Two recent studies suggested that a fraction of ceria (100) facets may form $\mathrm{CeO}_{4}$ terminated $\left(\mathrm{CeO}_{4}-\mathrm{t}\right)$ reconstructions, which yield a lower surface energy than cerium terminated (Ce-t) or O-t surfaces ${ }^{10,42}$. Therefore, DFT calculations were performed on a model comprising $\mathrm{CeO}_{4}$ - $\mathrm{t}$ reconstructions linked by $\mathrm{O}_{2 \mathrm{C}}$ sites $\left(\mathrm{CeO}_{4}\right.$-t surface, Fig. $\left.3 \mathrm{~b}\right)-\mathrm{a}$ pure $\mathrm{CeO}_{4}$-t reconstruction has previously been shown to have a high surface energy and is thus unstable ${ }^{10}$

First, the relative energies of dissociative and molecular adsorption were calculated for a single $\mathrm{H}_{2} \mathrm{O}$ molecule per $\mathrm{CeO}_{4}$-t surface unit (Supplementary Figs. 24-26). A comparison of the adsorption energies shows that $\mathrm{H}_{2} \mathrm{O}$ molecules also prefer to adsorb dissociatively on clean $\mathrm{CeO}_{4}$-t ceria (100) surfaces (Supplementary Table 9). The models $\mathrm{M}_{0}, \mathrm{M}_{1}, \mathrm{M}_{2}$ and $\mathrm{M}_{3}$ then correspond to $0,1,2$ and 3 dissociatively adsorbed $\mathrm{H}_{2} \mathrm{O}$ molecules per $\mathrm{CeO}_{4}$-t surface unit. The most energetically favorable $\mathrm{H}_{2} \mathrm{O}$ adsorption sites in $\mathrm{M}_{1}, \mathrm{M}_{2}$, and $\mathrm{M}_{3}$ were then determined by calculating and comparing the adsorption energies of several possible structural models (the lowest energy structure for each model is shown in Supplementary Figs. 26-28). The corresponding ${ }^{17} \mathrm{O}$ NMR calculation results for $\mathrm{M}_{0}, \mathrm{M}_{1}, \mathrm{M}_{2}$, and $\mathrm{M}_{3}$ are shown in Figs. 4 and 5, Supplementary Figs. 29-38 and Supplementary Tables 10-13 (also see more discussion in Supplementary Note 2 and Supplementary Fig. 39).

The $\mathrm{O}_{2 \mathrm{C}}$ ions in the first layer of models $\mathrm{M}_{0}$ and $\mathrm{M}_{1}$ are associated with very high chemical shifts of 1162 and $1168 \mathrm{ppm}$ respectively; such high frequency signals are not present in the experimental ${ }^{17} \mathrm{O}$ NMR spectra. This again indicates that these high energy, under-coordinated species have reacted with water to form more stable hydroxyl species, as observed in the ${ }^{1} \mathrm{H}$ and ${ }^{17} \mathrm{O}$ NMR spectra.

The calculated ${ }^{17} \mathrm{O}$ NMR shifts (center of gravity, $\delta_{\mathrm{CG}}$ ) based on the $\mathrm{CeO}_{4}$ - $\mathrm{t}$ model with two or three $\mathrm{H}_{2} \mathrm{O}$ molecules dissociatively adsorbed on each surface unit $\left(\mathrm{M}_{2}\right.$ and $\mathrm{M}_{3}$, Figs. 4 and 5, Supplementary Figs. 35-38, Supplementary Tables 12 and 13) are in good agreement with the experimental spectra. All the $\mathrm{O}_{2 \mathrm{C}}$ ions on the surface are consumed by reacting with $\mathrm{H}_{2} \mathrm{O}$ molecules to form hydroxyl groups, therefore there is no calculated signal at a shift higher than $1100 \mathrm{ppm}$, as observed experimentally. For the $\mathrm{O}_{3 \mathrm{C}}$ surface species in the $\mathrm{CeO}_{4}$ reconstruction, the calculated shifts in $\mathrm{M}_{2}$ are 943 and $968 \mathrm{ppm}$, which match the observed resonances at 935 and $970 \mathrm{ppm}$ in the experimental spectrum of $\mathrm{NCs}^{-17} \mathrm{O}_{2}$, while the calculated $\mathrm{O}_{3 \mathrm{C}}$ shifts in $\mathrm{M}_{3}$ are 910 and $996 \mathrm{ppm}$, in accordance with the experimental signals at 907 and $\sim 1012 \mathrm{ppm}$ for $\mathrm{NCs}-\mathrm{H}_{2}{ }^{17} \mathrm{O}$. The resonance at $\sim 1012 \mathrm{ppm}$ is quite broad, which is presumably due to a distribution of local environments caused by different arrangements of nearby dissociative $\mathrm{H}_{2} \mathrm{O}$ molecules. The observation that the resonant frequencies are higher for lower-coordinated oxygen ions on the surface is similar to the previous studies on ceria nanoparticles exposing (111) facets and titania nanostructures ${ }^{29,34}$.

The DFT calculations predict that the $\mathrm{O}_{4 \mathrm{C}}$ ions in the $2^{\text {nd }}$ or $3^{\text {rd }}$ layer for both $\mathrm{NCs}^{17} \mathrm{O}_{2}$ and $\mathrm{NCs}-\mathrm{H}_{2}{ }^{17} \mathrm{O}$ have resonant frequencies closer to the bulk shift of $877 \mathrm{ppm}$, which is consistent with the relatively broad component observed experimentally for the peak centered at $877 \mathrm{ppm}$. The predicted peak in the $2^{\text {nd }}$ layer at $756 \mathrm{ppm}$ for $\mathrm{M}_{2}$ is not experimentally observed; this environment, although fully coordinated, is highly distorted (see Supplementary Fig. 40). This distortion may be lost on addition of a bridging hydroxyl between the $\mathrm{CeO}_{4}$ reconstructions (e.g. $\mathrm{H}_{4}$, see Fig. 6), which is above the distorted environment, or the distortion may be averaged at non-zero temperatures due to rapid interconversion of different local environments with similar energies. 
a

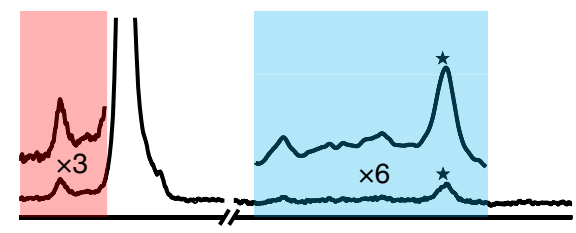

b

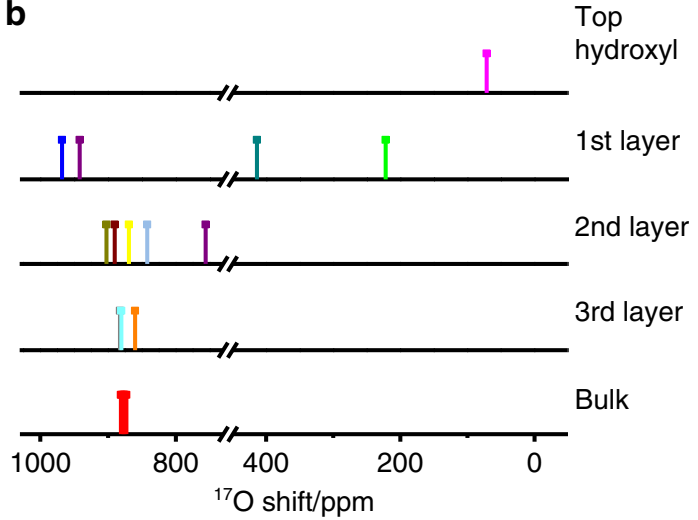

$\mathrm{NCs}-{ }^{17} \mathrm{O}_{2}$

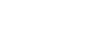

op

tayer

nd layer

dayer

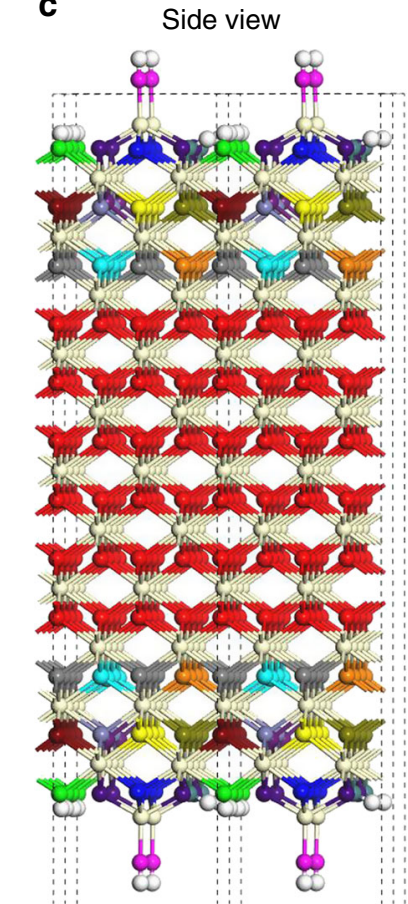

${ }^{17} \mathrm{O} \delta_{\mathrm{CG}} / \mathrm{ppm}$

71
$222968943 \quad 414$

890841869902756

883880860

$\begin{array}{llll}873 & 875 & 881 & 884\end{array}$

875877878881

876878

876878

875877878881

873875881884

883880860

890841869902756

222968943414

71

Bottom hydroxyl

Fig. $4{ }^{17} \mathrm{O}$ NMR spectrum, calculated ${ }^{17} \mathrm{O}$ NMR shifts and the structure model of ceria $\mathrm{NCs}^{-17} \mathrm{O}_{2} \cdot \mathbf{a}^{17} \mathrm{O}$ Solid-State NMR spectra of ceria NCs-17 $\mathrm{O}_{2}($ shown in Fig. 1). b The summarized ${ }^{17} \mathrm{O}$ NMR shifts $\left(\delta_{\mathrm{CG}} \mathrm{S}\right)$ predicted for the $\mathrm{CeO}_{4}$-t model with two $\mathrm{H}_{2} \mathrm{O}$ molecules dissociatively adsorbed on each surface unit $\left(\mathrm{M}_{2}\right)$. c The hydrated $\mathrm{CeO}_{4}$-t model used in the DFT calculations with NMR shifts $\left(\delta_{\mathrm{CG}} \mathrm{s}\right)$ for oxygen ions and the layer number shown on the right. Red, offwhite, and white balls represent bulk oxygen, cerium, and hydrogen ions, respectively. Surface oxygen ions with different shifts are shown in different colors. The calculated ${ }^{17} \mathrm{O}$ NMR parameters for each oxygen ion are shown in Supplementary Table 12. A line broadening of 600 was applied to the enlarged spectrum in the blue region, no line broadening was applied to the enlarged spectrum in the red region.

a

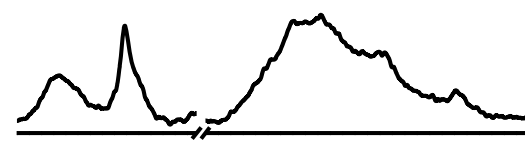

b

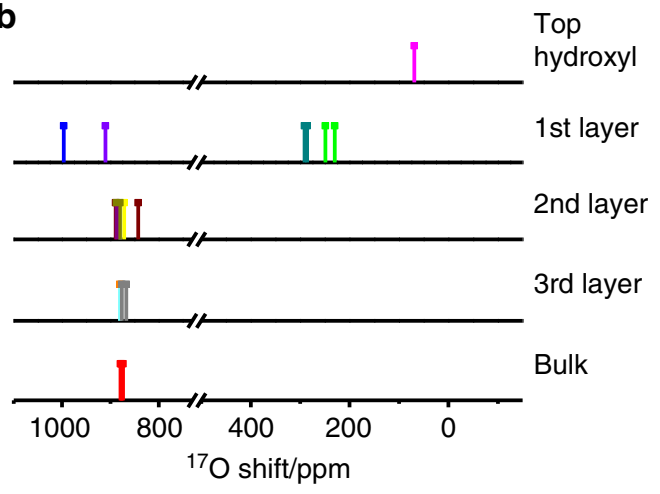

C

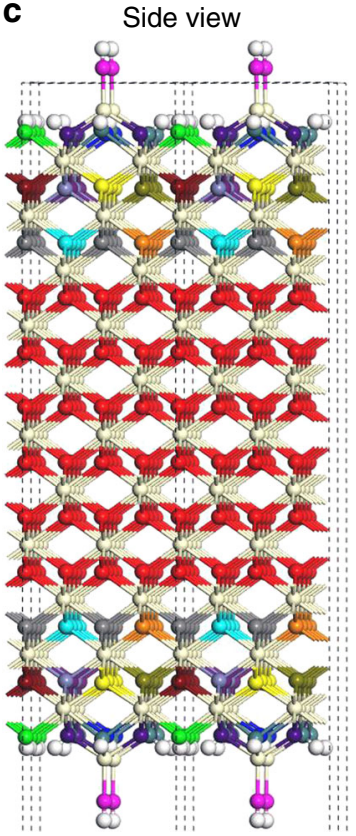

${ }^{17} \mathrm{O} \delta_{\mathrm{CG}} / \mathrm{ppm}$

69

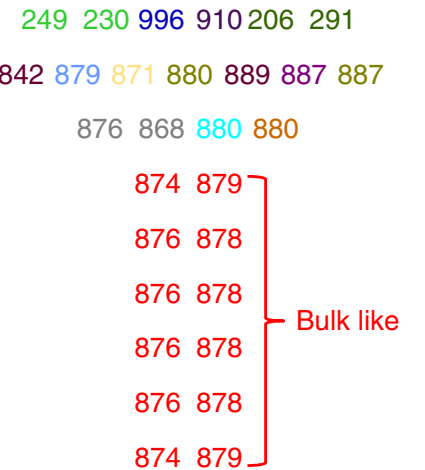

876868880880

842879871880889887887

249230996910206291

69
Layer

Top hydroxyl

1

2

3

4

5

6

7

8

9

10

11

12

Bottom hydroxyl

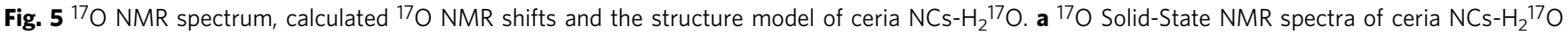
(shown in Fig. 1). b The summarized ${ }^{17} \mathrm{O}$ NMR shifts $\left(\delta_{\mathrm{CG}} \mathrm{S}\right)$ predicted for the $\mathrm{CeO}_{4}$-t model with three $\mathrm{H}_{2} \mathrm{O}$ molecules dissociatively adsorbed on each surface unit $\left(\mathrm{M}_{3}\right)$. c The hydrated $\mathrm{CeO}_{4}$-t model used in the DFT calculations with calculated NMR shifts $\left(\delta_{\mathrm{CG}} \mathrm{S}\right)$ for oxygen ions and the layer number shown on the right. Red, off-white, and white balls represent bulk oxygen, cerium, and hydrogen ions, respectively. Surface oxygen ions with different shifts are shown in different colors. The calculated ${ }^{17} \mathrm{O}$ NMR parameters for each oxygen ion are shown in Supplementary Table 13. 


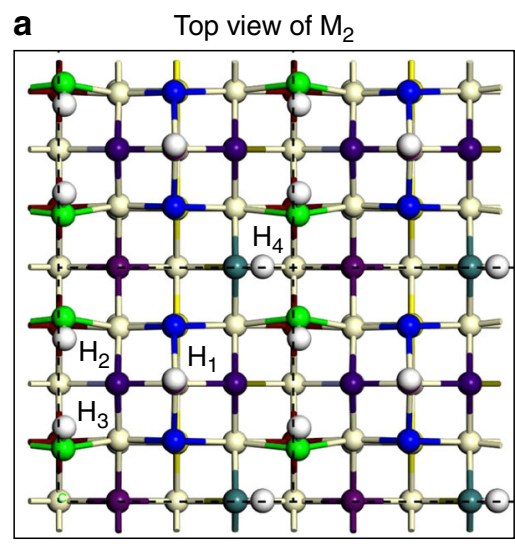

b

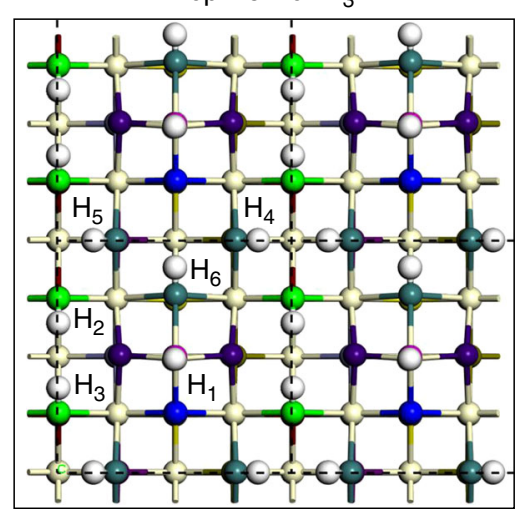

Fig. 6 Structure of $M_{2}$ and $M_{3}$. White and off-white spheres represent hydrogen and cerium ions, respectively, in the top view of $M_{2}$ (a) and $M_{3}$ (b). Surface oxygen groups with different chemical shifts are in different colors. For each $\mathrm{CeO}_{4}$-t surface unit of $\mathrm{M}_{2}$, four hydrogen ions labeled as $\mathrm{H}_{1}, \mathrm{H}_{2}, \mathrm{H}_{3}$, and $\mathrm{H}_{4}$ form from the two dissociative $\mathrm{H}_{2} \mathrm{O}$ molecules while for each $\mathrm{CeO}_{4}$-t surface unit of $\mathrm{M}_{3}$, six hydrogen ions labeled as $\mathrm{H}_{1}, \mathrm{H}_{2}, \mathrm{H}_{3}, \mathrm{H}_{4}$, $\mathrm{H}_{5}$, and $\mathrm{H}_{6}$ form from the three dissociative $\mathrm{H}_{2} \mathrm{O}$ molecules.

Terminal hydroxyl sites $\left(-\mathrm{OH}_{\mathrm{T}}\right)$ are calculated to have ${ }^{17} \mathrm{O}$ shifts $\left(\delta_{\mathrm{CG}} \mathrm{s}\right)$ of $69 \mathrm{ppm}$ for $\mathrm{M}_{2}$ and $71 \mathrm{ppm}$ for $\mathrm{M}_{3}$, while bridging hydroxyl sites $\left(-\mathrm{OH}_{\mathrm{B}}\right)$ for both samples have calculated ${ }^{17} \mathrm{O}$ shifts $\left(\delta_{\mathrm{CG}} \mathrm{s}\right)$ of $206-291 \mathrm{ppm}$. These sites are predicted to have relatively large $C_{\mathrm{Q}} \mathrm{s}(5.5-7.6 \mathrm{MHz})$, thus the corresponding resonances are expected to exhibit significant second order quadrupolar broadening. This agrees well with the broad resonance observed at lower shifts in the experimental spectrum of $\mathrm{NCs}-\mathrm{H}_{2}{ }^{17} \mathrm{O}$; the hydroxyl groups have been largely unenriched for $\mathrm{NCs}^{-17} \mathrm{O}_{2}$, see above.

The above results indicate that the concentration of surface hydroxyl groups has a great impact on the NMR shifts of surface oxygen ions. Furthermore, in order to reproduce the experimental ${ }^{17} \mathrm{O}$ NMR spectra, both dissociated water and $\mathrm{CeO}_{4}$-t reconstructions must be included in the calculations. Thus, the ceria (100) surface can be regarded as a combination of $\mathrm{CeO}_{4}-\mathrm{t}$ and $\mathrm{O}-\mathrm{t}$ surface units, where the under-coordinated $\mathrm{O}_{2 \mathrm{C}}$ ions have been converted to bridging hydroxyl groups and terminal hydroxyl groups have formed on some under-coordinated cerium ions.

The ${ }^{1} \mathrm{H}$ NMR chemical shifts were also calculated using DFT, confirming the assignment of the ${ }^{1} \mathrm{H}$ NMR signals at 2-16 ppm and $2.5 \mathrm{ppm}$ to bridging $\left(-\mathrm{OH}_{\mathrm{B}}\right)$ and terminal $\left(-\mathrm{OH}_{\mathrm{T}}\right)$ hydroxyl groups on the surface (Fig. 6 and Table 1$)^{38,39}$. The calculated ${ }^{1} \mathrm{H}$ shift for $-\mathrm{OH}_{\mathrm{T}}$ is the most negative, and since the lowest frequency signal in the experimental ${ }^{1} \mathrm{H}$ NMR spectrum is the relatively sharp peak at $2.5 \mathrm{ppm}$, this resonance is assigned to
Table 1 Calculated ${ }^{1} \mathbf{H}$ NMR chemical shifts ${ }^{a}$ for $M_{2}$ and $M_{3}$. The corresponding structures are presented in Fig. 6.

\begin{tabular}{|c|c|c|c|c|}
\hline \multirow[t]{2}{*}{$H_{\text {ion }}$ No. } & \multicolumn{2}{|l|}{$\mathbf{M}_{2}$} & \multicolumn{2}{|l|}{$\mathbf{M}_{3}$} \\
\hline & $\delta_{\text {iso }} / \mathrm{ppm}$ & Assignment & $\delta_{\text {iso }} / \mathrm{ppm}$ & Assignment \\
\hline 1 & 2.50 & $-\mathrm{OH}_{\mathrm{T}}$ & 2.50 & $-\mathrm{OH}_{\mathrm{T}}$ \\
\hline 2 & 5.56 & $-\mathrm{OH}_{\mathrm{B}}$ & 5.72 & $-\mathrm{OH}_{\mathrm{B}}$ \\
\hline 3 & 5.70 & $-\mathrm{OH}_{\mathrm{B}}$ & 4.79 & $-\mathrm{OH}_{\mathrm{B}}$ \\
\hline 4 & 10.18 & $-\mathrm{OH}_{\mathrm{B}}$ & 7.07 & $-\mathrm{OH}_{\mathrm{B}}$ \\
\hline 5 & - & - & 6.95 & $-\mathrm{OH}_{\mathrm{B}}$ \\
\hline 6 & - & - & 5.38 & $-\mathrm{OH}_{\mathrm{B}}$ \\
\hline \multicolumn{5}{|c|}{$\begin{array}{l}\text { aThe chemical shifts }\left(\delta_{\text {iso }}\right) \text { are referenced to the experimental chemical shift of the terminal } \\
\text { hydroxyl }(2.50 \mathrm{ppm}) \text { (Supplementary Figs. } 41 \text { and } 42) \text { and summarized under the }{ }^{1} \mathrm{H} \text { spectra in } \\
\text { Fig. } 2 \mathrm{a}, \mathrm{b}\end{array}$} \\
\hline
\end{tabular}

Table 2 The contents of terminal hydroxyls $\left(-\mathrm{OH}_{\mathrm{T}}\right.$ and $\left.-\mathrm{OH}_{\mathrm{B}}\right)$ and different surface units.

\begin{tabular}{|c|c|c|c|c|}
\hline \multirow[t]{2}{*}{ Sample } & \multicolumn{2}{|c|}{ Hydroxyla/\% } & \multicolumn{2}{|c|}{ Surface Unit/\% } \\
\hline & $-\mathrm{OH}_{\mathbf{T}}$ & $-\mathrm{OH}_{\mathrm{B}}$ & O-t & $\mathrm{CeO}_{4}-\mathrm{t}$ \\
\hline $\mathrm{NCs}-{ }^{17} \mathrm{O}_{2}$ & 6.3 & 86.1 & 57.1 & 42.9 \\
\hline $\mathrm{NCs}-\mathrm{H}_{2}{ }^{17} \mathrm{O}$ & 5.6 & 88.6 & 57.5 & 42.5 \\
\hline
\end{tabular}

$-\mathrm{OH}_{\mathrm{T}}$. The broad signal is attributed to $-\mathrm{OH}_{\mathrm{B}}$. Different $-\mathrm{OH}_{\mathrm{B}}$ environments are associated with a range of chemical shifts and the distribution is wider for the model with three dissociatively adsorbed $\mathrm{H}_{2} \mathrm{O}$ molecules $\left(\mathrm{M}_{3}\right)$ than that for two $\left(\mathrm{M}_{2}\right)$; in particular, the very large shift of $\mathrm{H}_{4}$ in $\mathrm{M}_{2}$ is due to hydrogen bonding to the oxygen ions of $\mathrm{H}_{2}$ and $\mathrm{H}_{3}$. This at least partially explains why the experimental $-\mathrm{OH}_{\mathrm{B}}$ resonance is broad and why the spectral line width for $\mathrm{NCs}-\mathrm{H}_{2}{ }^{17} \mathrm{O}$ is broader than for NCs${ }^{17} \mathrm{O}_{2}$, given the higher hydroxyl content of the former. An inhomogeneous distribution of dissociated water and variable hydrogen bonding may also contribute to the broadness of the signals.

Based on the quantitative ${ }^{1} \mathrm{H}$ NMR data and the above assignments from the DFT calculations, the fractions of $\mathrm{CeO}_{4}-\mathrm{t}$ and O-t surface units comprising the (100) facets of ceria nanocubes can be determined (Table 2). This is based on the fact that each $\mathrm{CeO}_{4}$-t surface unit contains one characteristic terminal hydroxyl group $\left(-\mathrm{OH}_{\mathrm{T}}\right)$ and either three $\left(\mathrm{M}_{2}\right.$, Fig. 2a) or five $\left(\mathrm{M}_{3}\right.$, Fig. 2b) bridging hydroxyl groups $\left(-\mathrm{OH}_{\mathrm{B}}\right)$, while each hydroxylated $\mathrm{O}$-t surface unit contains eight bridging hydroxyls $\left(-\mathrm{OH}_{\mathrm{B}}\right)$ (Supplementary Fig. 21). The fractions of $\mathrm{CeO}_{4}$-t and O-t surface units calculated for $\mathrm{NCs}^{-17} \mathrm{O}_{2}(57.1 \%$ for $\mathrm{O}-\mathrm{t}$ and $42.9 \%$ for

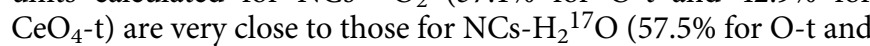
$42.5 \%$ for $\mathrm{CeO}_{4}-\mathrm{t}$ ), supporting the assignment of these models.

${ }^{17}$ O DNP NMR spectroscopy. Recent developments in dynamic nuclear polarization (DNP) provide new opportunities to characterize the surface structure of solid materials ${ }^{34,43,44}$. Direct DNP involves transferring polarization from unpaired electrons directly to the nucleus of interest, with the unpaired electrons typically being added in the form of organic biradicals; because the biradicals are external to the particles, and the hyperpolarization mechanism has a $1 / \mathrm{r}^{6}$ distance dependence, the surface can be selectively hyperpolarized and hence observed in the NMR spectrum (surface enhanced NMR spectroscopy, SENS). Indirect DNP, where ${ }^{1} \mathrm{H}$ nuclei are first hyperpolarized before 


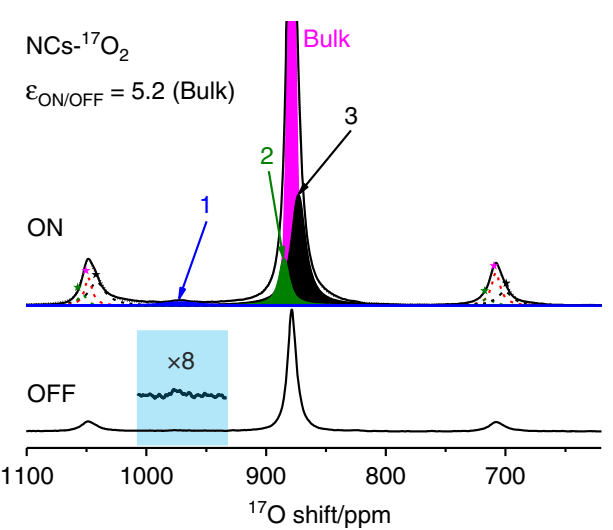

C

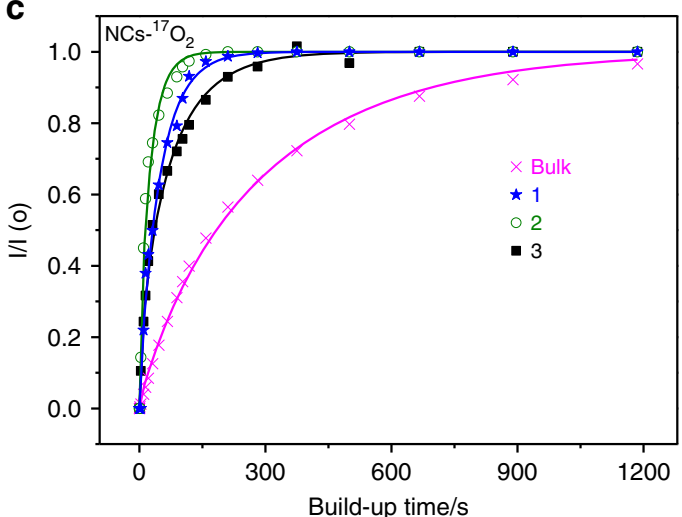

b
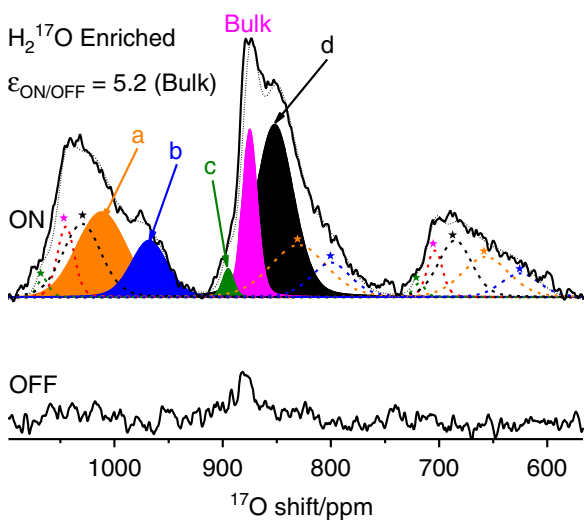

d

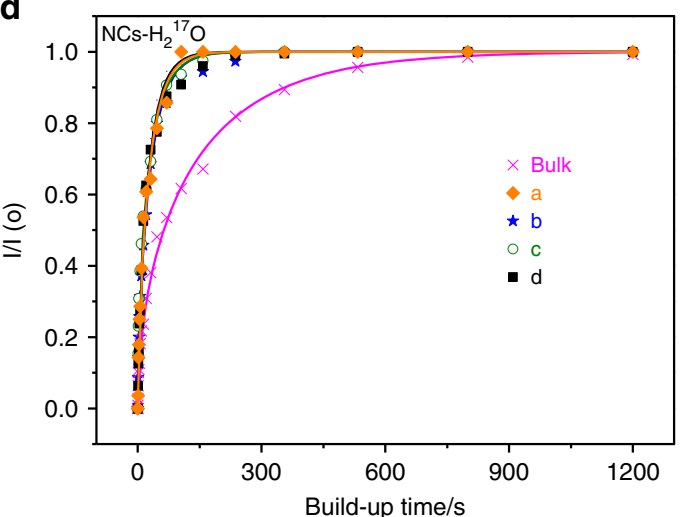

Fig. $7{ }^{17} \mathrm{O}$ DNP NMR spectra and saturation recovery data of $\mathrm{NCs}_{-}{ }^{17} \mathrm{O}_{2}$ and $\mathrm{NCs}-\mathrm{H}_{2}{ }^{17} \mathrm{O}$. Deconvoluted ${ }^{17} \mathrm{O}$ direct DNP NMR spectra, with and without microwave irradiation of $\mathbf{a} \mathrm{NCs}^{-17} \mathrm{O}_{2}$ and $\mathbf{b} \mathrm{NCs}-\mathrm{H}_{2}{ }^{17} \mathrm{O}$ mixed with the TEKPol radical in dried TCE. The spectra were measured at $100 \mathrm{~K}$ at a spinning speed of $13.9 \mathrm{kHz}$. A pre-saturated rotor synchronized Hahn-echo pulse sequence $(\pi / 2-\tau-\pi$ - $\tau$-acquisition) and a recycle delay of $60 \mathrm{~s}$ were utilized. Stars denote spinning sidebands. c, d The corresponding ${ }^{17} \mathrm{O}$ direct DNP saturation recovery build-up curves of the deconvoluted isotropic resonances in $\mathbf{a}$ and $\mathbf{b}$. The build-up time $\left(T_{\mathrm{DNP}}\right)$ was determined by deconvoluting the spectrum and fitting the peak areas to a stretched exponential function of the form $\frac{I(t)}{I_{0}}=1-e^{-\left(\frac{t}{T_{\mathrm{DNP}}}\right)^{\beta}}$, where $I(t)$ and $I_{0}$ are the signal intensities at delay $t$ and at equilibrium, respectively, and $\beta$ is the stretching exponent $(0<\beta<1)($ Table 3$)$.

cross-polarization to the nucleus of interest, can yield greater enhancements in some cases, but for ${ }^{17} \mathrm{O}$ NMR only oxygen atoms directly bonded to $\mathrm{H}$ can be observed, so indirect DNP cannot be used to detect the unhydroxylated (sub-)surface oxygen environments $^{34}$. Therefore, direct DNP SENS was applied to study ceria nanocubes and aid spectral assignments. The intensities for the bulk ${ }^{17} \mathrm{O}$ peak at $875 \mathrm{ppm}$ are 5.2 times stronger with microwave irradiation than without, for both $\mathrm{NCs}^{-17} \mathrm{O}_{2}$ and $\mathrm{NCs}-\mathrm{H}_{2}{ }^{17} \mathrm{O}$ (Fig. 7a, b). For $\mathrm{NCs}^{17} \mathrm{O}_{2}$, the enhancement factor for the peak at $970 \mathrm{ppm}$ is $\sim 8$, while the surface signals for NCs$\mathrm{H}_{2}{ }^{17} \mathrm{O}$ can only be observed in the "on" spectrum, indicating that hyperpolarization is more efficient for these species than for the bulk, and therefore that these resonances are indeed surface oxygen species.

The DNP build-up time, $T_{\mathrm{DNP}}$, can also be fitted to distinguish external and internal ${ }^{17} \mathrm{O}$ nuclei ${ }^{34}$, since nuclei close to the surface hyperpolarize faster and hence have a shorter $T_{\mathrm{DNP}}$. For NCs- ${ }^{17} \mathrm{O}_{2}$, the $T_{\mathrm{DNP}}$ values for the peaks at 970,880 , and 870 ppm are much smaller than for the bulk signal at $875 \mathrm{ppm}$, implying that the former arise from surface species in $\mathrm{NCs}^{-17} \mathrm{O}_{2}$ (Fig. 7c and Table 3). Broader peaks are observed for the ${ }^{17} \mathrm{O}$ DNP SENS spectra than for the room temperature ${ }^{17} \mathrm{O}$ spectra, which can be attributed to the freezing out of motional averaging of the dynamic surface sites at the low temperatures required for DNP, as previously observed for ceria (111) facets ${ }^{34}$.

\begin{tabular}{|c|c|c|c|c|c|c|c|c|c|}
\hline & \multicolumn{4}{|c|}{$\mathbf{N C s}-{ }^{17} \mathrm{O}_{2}$} & \multicolumn{5}{|c|}{ NCs- $\mathrm{H}_{2}{ }^{17} \mathrm{O}$} \\
\hline & Bulk & 1 & 2 & 3 & Bulk & $\mathbf{a}$ & b & c & d \\
\hline$\delta_{\text {iso }} / \mathrm{ppm}$ & 875 & 970 & 880 & 870 & 875 & 1012 & 970 & 895 & 853 \\
\hline$T_{\mathrm{DNP}} / \mathrm{s}$ & 329 & 53 & 30 & 95 & 212 & 23 & 38 & 40 & 31 \\
\hline$\beta$ & 0.8 & 0.8 & 0.7 & 0.6 & 0.5 & 0.8 & 0.7 & 0.6 & 0.7 \\
\hline
\end{tabular}

The ${ }^{17} \mathrm{O}$ DNP spectrum of $\mathrm{NCs}-\mathrm{H}_{2}{ }^{17} \mathrm{O}$ has spinning sidebands which overlap with other resonances due to the lower spinning speeds achievable at $100 \mathrm{~K}$ and the higher field at which the DNP experiments were performed (which results in a smaller separation of sidebands in ppm, for the same spinning frequency). Therefore, ${ }^{17} \mathrm{O}$ DNP projection magic angle turning and phase adjusted sideband separation (MATPASS) NMR experiments were performed to resolve the isotropic resonances (Supplementary Fig. 43) 45,46. Four non-bulk resonances at 1012, 970,895 , and $853 \mathrm{ppm}$ can be deconvoluted, and were used to fit the saturation recovery data and obtain the $T_{\mathrm{DNP}}$ (Fig. $7 \mathrm{~d}$ and Table 3). Again, these peaks are associated with shorter $T_{\mathrm{DNP}}$ than the peak at $875 \mathrm{ppm}$ arising from the bulk part of the 
sample, in agreement with our assignments from conventional ${ }^{17} \mathrm{O}$ NMR spectroscopy.

\section{Discussion}

${ }^{17} \mathrm{O}$ and ${ }^{1} \mathrm{H}$ solid-state NMR spectroscopy, combined with DFT calculations, were employed to determine the surface structure of ceria (100) polar surfaces. The results obtained in this work provide compelling evidence that $\mathrm{CeO}_{4}$ - $\mathrm{t}$ reconstructions and hydroxyl groups are present on the surface of ceria nanocubes, both of which are expected to reduce the surface energy and afford polarity compensation. The amount of hydroxyl groups alters the ${ }^{17} \mathrm{O}$ NMR shifts of oxygen ions at the surface of the nanocubes, making ${ }^{17} \mathrm{O}$ a very sensitive probe for the surface structure and, therefore, its properties. Furthermore, the fractions of $\mathrm{CeO}_{4}$ - $\mathrm{t}$ and $\mathrm{O}$-t surface units can be determined with quantitative ${ }^{1} \mathrm{H}$ NMR measurements. DNP SENS results confirm the ${ }^{17} \mathrm{O}$ spectral assignments, however, although DNP SENS spectroscopy generally provides a stronger signal-to-noise ratio compared to conventional NMR spectroscopy, due to the restricted spinning rates and broader surface signals at low temperature, certain species can be resolved better with the latter. The strategy introduced here can be applied to gain insight into the surface structures of oxide nanocrystals and materials with polar surfaces.

\section{Methods}

Preparation of ceria nanocubes. In a typical synthesis procedure ${ }^{47}, 1.96 \mathrm{~g} \mathrm{Ce}$ $\left(\mathrm{NO}_{3}\right)_{3} \cdot 6 \mathrm{H}_{2} \mathrm{O}$ was added into $40 \mathrm{~mL}$ distilled water. After stirring for $5 \mathrm{~min}, 30 \mathrm{~mL}$ $\mathrm{NaOH}$ solution $(\mathrm{pH}=14)$ was slowly added into the mixture before it was vigorously stirred for another $30 \mathrm{~min}$ at room temperature. The mixture was then transferred into a $100 \mathrm{~mL}$ Teflon-lined hydrothermal reactor and heated at $453 \mathrm{~K}$ for $24 \mathrm{~h}$ before it was allowed to cool to room temperature. The resulting white sediment was centrifuged, washed with distilled water and dried at $353 \mathrm{~K}$ overnight. Finally, the solid was annealed in a tube furnace at $573 \mathrm{~K}$ for $5 \mathrm{~h}$ in flowing oxygen gas to obtain calcined ceria nanocubes.

Characterization. Powder X-Ray Diffraction (XRD) characterization was performed with a Philips X'Pro X-ray diffractometer with $\mathrm{Cu} \mathrm{Ka}$ irradiation $(\lambda=$ $1.54184 \AA$ ) operating at $40 \mathrm{kV}$ and $40 \mathrm{~mA}$. High-Resolution Transmission Electron Microscope (HRTEM) images were recorded on a JEOL JEM-2010 instrument at an acceleration voltage of $200 \mathrm{kV}$. X-ray Photoelectron Spectra (XPS) were measured on a Thermo ESCALAB $250 \mathrm{X}$ with $\mathrm{Al} \mathrm{Ka}(h v=1486.6 \mathrm{eV})$ as the excitation source. The binding energies in XPS spectra were referenced to C $1 \mathrm{~s}=284.8 \mathrm{eV}$. Brunauer-Emmett-Teller (BET) specific surface area information was obtained from nitrogen adsorption at $77 \mathrm{~K}$ on a Micromeritics ASAP 2020 system. Raman spectra were acquired with a Bruker Multi RAM FT-Raman spectrometer using $514 \mathrm{~nm}$ light from a $\mathrm{He}-\mathrm{Ne}$ laser source. The content of $\mathrm{Na}$ ions was analyzed by an Optima 5300DV inductively coupled plasma mass spectrometer (ICP-MS) while the $\mathrm{N}$ content was determined with a Heraeus $\mathrm{CHN}-0$-Rapid elemental analyzer.

${ }^{17} \mathrm{O}$ Isotopic labeling procedure. Ceria nanocubes were ${ }^{17} \mathrm{O}$-labeled on a vacuum line with commercial $90 \%{ }^{17} \mathrm{O}$-enriched $\mathrm{O}_{2}$ gas and $\mathrm{H}_{2} \mathrm{O}$, respectively (Isotec Inc.). In a typical ${ }^{17} \mathrm{O}$ isotopic labeling procedure, $200 \mathrm{mg}$ sample was placed in a glass tube and calcined at $523 \mathrm{~K}$ under $1 \times 10^{-3}$ Torr for $3 \mathrm{~h}$, in order to remove most of the physically adsorbed water and surface hydroxyl groups. The nanocubes were allowed to cool down to room temperature before ${ }^{17} \mathrm{O}_{2}$ gas or $\mathrm{H}_{2}{ }^{17} \mathrm{O}$ vapor was introduced into the glass tube. The glass tube was sealed and then heated to the target temperature (523 K for ${ }^{17} \mathrm{O}_{2}$ and $373 \mathrm{~K}$ for $\mathrm{H}_{2}{ }^{17} \mathrm{O}$ labeling) for $10 \mathrm{~h}$. After the enrichment with $\mathrm{H}_{2}{ }^{17} \mathrm{O}$, the samples were exposed to vacuum to remove physisorbed water.

Solid-State NMR Spectroscopy. ${ }^{17} \mathrm{O}$ and ${ }^{1} \mathrm{H}$ Magic Angle Spinning Nuclear Magnetic Resonance (MAS NMR) experiments were recorded on a Bruker Avance III 400 spectrometer equipped with an $89 \mathrm{~mm}$ wide-bore $9.4 \mathrm{~T}$ superconducting magnet yielding Larmor Frequencies of 54.2 and $400 \mathrm{MHz}$, respectively. All of the samples were packed into $3.2 \mathrm{~mm}$ rotors inside a $\mathrm{N}_{2}$-filled glove box. ${ }^{17} \mathrm{O}$ and ${ }^{1} \mathrm{H}$ chemical shifts are referenced to $\mathrm{H}_{2} \mathrm{O}$ at $0.0 \mathrm{ppm}$ and to adamantane at $1.92 \mathrm{ppm}$, respectively.

${ }^{17} \mathrm{O}$ direct dynamic nuclear polarization (DNP) NMR experiments were performed at a Larmor frequency of $81.3 \mathrm{MHz}$ on a $14.1 \mathrm{~T}$ Bruker Avance III HD 600 spectrometer equipped with a $395 \mathrm{GHz}$ gyrotron microwave source and a $3.2 \mathrm{~mm}$ MAS probe. The microwave source power applied for ${ }^{17} \mathrm{O}$ direct DNP measurements was $7.0 \mathrm{~W} .{ }^{17} \mathrm{O}$ labeled ceria nanocubes were mixed with radical solution $\left(16 \mathrm{mM}\right.$ TEKPol ${ }^{44}$ in dried tetrachloroethane, TCE) in an Ar-filled glove box. ${ }^{17} \mathrm{O}$ chemical shifts of the DNP NMR spectra were referenced to bulk ceria at $875 \mathrm{ppm}$ at $100 \mathrm{~K}$.

Details of DFT calculations. All spin-polarized DFT calculations were carried out using the Vienna Ab initio Simulation Package $(V A S P)^{48}$. The Perdew-BurkeErnzerhof (PBE) functional ${ }^{49}$ with the Hubbard $U$ correction $(\mathrm{DFT}+U)^{50}$ were used for all calculations. The effective $U$ value of $5.0 \mathrm{eV}$ was only applied to the localized Ce $4 f$ orbitals $^{51,52}$; our previous study shows that the calculated chemical shifts from $\mathrm{PBE}+U(5.0 \mathrm{eV})$ are in quantitative agreement with the experimental values $^{28}$. The projector augmented wave method ${ }^{53}$ was used to describe the interaction between core and valence electrons. A plane-wave kinetic energy cutoff of $500 \mathrm{eV}$ was used for all calculations. For geometry optimization, all of the atoms were allowed to relax until the Hellman-Feynman forces were lower than $0.02 \mathrm{eV}$ $\AA^{-1}$. For electronic minimization, we used an energy convergence criterion of $10^{-5} \mathrm{eV}$ for optimizing geometries and a higher criterion of $10^{-8} \mathrm{eV}$ for chemical shift and electric field gradients (EFGs) calculations ${ }^{28}$. The optimized lattice parameter of ceria using $\mathrm{PBE}+U(5.0 \mathrm{eV})$ is $5.448 \AA$, which is in reasonable agreement with the experimental value $(5.411 \AA)^{54}$.

We used a $2 \times 2$ surface cell to model the ceria (100) surface. The ceria (100) surface slab model with 12 oxygen layers was found to be sufficiently thick, i.e., the middle layers of this model mimic the bulk environment in terms of chemical shift (Supplementary Figs. 9, 12, 15, 18, 22, 30, 33, 36 and 38). All the slabs contain a large vacuum gap $(>10 \AA)$ to remove the slab-slab interactions. The $k$-point mesh was sampled by using a $2 \times 2 \times 1$ Monkhorst-Pack grid.

We used the same method as our previous work ${ }^{28}$ to calculate chemical shifts, quadrupole coupling constants $\left(C_{\mathrm{Q}}\right)$ and asymmetry parameters $(\eta)$. For the electric EFG calculations to obtain $C_{\mathrm{Q}}$ and $\eta$ of oxygen species, we used the experimental quadrupole moment $(Q)$ of -0.02558 barns ${ }^{55}$ for ${ }^{17} \mathrm{O}$. For calculating the isotropic chemical shift $\left(\delta_{\text {iso }}\right)$, we used the following equation:

$$
\delta_{\text {iso }}=\delta_{\text {cal }}+\delta_{\text {ref }},
$$

where $\delta_{\text {cal }}$ is the unaligned DFT chemical shift, $\delta_{\text {ref }}$ is the reference chemical shift. The averaged value of the unaligned DFT chemical shifts of oxygen species in the middle layers (layers 4-9) of every prototype slab models is $835 \mathrm{ppm}$. By aligning $835 \mathrm{ppm}$ to the corresponding experimental value of $877 \mathrm{ppm}$, we obtained the $\delta_{\text {ref }}$ of 42 ppm.

The average adsorption energies of each water molecule $\left(E_{\text {ads }}\right)$ on the (100) surface with the $\mathrm{O}$-t or $\mathrm{CeO}_{4}$-t model were calculated as the following:

$$
E_{\text {ads }}=1 / n \cdot\left\{E\left[n \mathrm{H}_{2} \mathrm{O} / \mathrm{CeO}_{2}\right]-E\left[\mathrm{CeO}_{2}\right]-n E\left[\mathrm{H}_{2} \mathrm{O}\right]\right\}
$$

where $n$ is the number of adsorbed water molecules, $E\left[n \mathrm{H}_{2} \mathrm{O} / \mathrm{CeO}_{2}\right], E\left[\mathrm{CeO}_{2}\right]$ and $E\left[\mathrm{H}_{2} \mathrm{O}\right]$ are the DFT calculated total energies of the adsorption complex, the ceria substrate and the gas phase $\mathrm{H}_{2} \mathrm{O}$ molecule, respectively.

Thermodynamic stabilities of different water adsorption structures on O-t and $\mathrm{CeO}_{4}$-t surface units at given water partial pressure and temperature were determined by calculating the surface free energy per unit area $(\gamma(p, T))^{41,56,57}$ :

$\gamma(p, T)=1 / A \cdot\left\{G_{\text {slab }}\left[n \mathrm{H}_{2} \mathrm{O} / \mathrm{CeO}_{2}\right](p, T)-m G_{\text {bulk }}\left[\mathrm{CeO}_{2}\right](p, T)-n \mu\left[\mathrm{H}_{2} \mathrm{O}\right](p, T)\right\}$,

where $A$ is the surface area of the slab, $n$ is the number of adsorbed water molecules, $m$ is the number of $\mathrm{CeO}_{2}$ bulk (i.e., $\mathrm{Ce}_{4} \mathrm{O}_{8}$ ) units in the slab model, $\mu$ is the chemical potential, and $G$ is the Gibbs free energy.

We assumed that the surfaces are in thermodynamic equilibrium with gas phase $\mathrm{H}_{2} \mathrm{O}$. So, $\mu\left[\mathrm{H}_{2} \mathrm{O}\right](p, T)$ can be calculated as follows:

$$
\begin{aligned}
\mu\left[\mathrm{H}_{2} \mathrm{O}\right](p, T)= & E\left[\mathrm{H}_{2} \mathrm{O}\right]+\Delta \mu\left[\mathrm{H}_{2} \mathrm{O}\right](p, T)=E\left[\mathrm{H}_{2} \mathrm{O}\right]+H\left[\mathrm{H}_{2} \mathrm{O}\right]\left(p^{0}, T\right) \\
& -H\left[\mathrm{H}_{2} \mathrm{O}\right]\left(p^{0}, O K\right)-T S\left[\mathrm{H}_{2} \mathrm{O}\right]\left(p^{0}, T\right)+K_{B} T \ln \left(p / p^{0}\right),
\end{aligned}
$$

where $p^{0}$ is the standard state pressure $(0.1 \mathrm{MPa})$; enthalpy $(H)$ and entropy $(S)$ terms were taken from the website of NIST ${ }^{58}$. As the DFT total energies of the solid components can be regarded as good approximations of corresponding Gibbs free energies $^{57}$, we then obtained:

$$
\begin{aligned}
\gamma(p, T)= & 1 / A \cdot\left\{G_{\text {slab }}\left[\mathrm{nH}_{2} \mathrm{O} / \mathrm{CeO}_{2}\right](p, T)-m G_{b u l k}\left[\mathrm{CeO}_{2}\right](p, T)-n E\left[\mathrm{H}_{2} \mathrm{O}\right]\right. \\
& \left.-n H\left[\mathrm{H}_{2} \mathrm{O}\right]\left(p^{0}, T\right)+n H\left[\mathrm{H}_{2} \mathrm{O}\right]\left(p^{0}, 0 K\right)+n T S\left[\mathrm{H}_{2} \mathrm{O}\right]\left(p^{0}, T\right)-n K_{B} T \ln \left(p / p^{0}\right)\right\},
\end{aligned}
$$

Note that the vibration contributions and the $p V$ ( $V$ denotes volume) term of solid components were not considered.

\section{Data availability}

The data that support the findings of this study are available from the corresponding author upon reasonable request.

Received: 6 March 2019; Accepted: 7 November 2019; Published online: 28 November 2019 


\section{References}

1. Kong, X. Y., Ding, Y. \& Wang, Z. L. Single crystal nanorings formed by epitaxial self coiling of polar nanobelts. Science 303, 1348-1351 (2004).

2. Yu, L. \& Zunger, A. A polarity-induced defect mechanism for conductivity and magnetism at polar-nonpolar oxide interfaces. Nat. Commun. 5, 5118 (2014).

3. Métois, J. J., Saúl, A. \& Müller, P. Measuring the surface stress polar dependence. Nat. Mater. 4, 238-242 (2005).

4. Wang, Z. L. et al. Semiconducting and piezoelectric oxide nanostructures induced by polar surfaces. Adv. Funct. Mater. 14, 943-956 (2004).

5. Mclaren, A. et al. Shape and size effects of $\mathrm{ZnO}$ nanocrystals on photocatalytic activity. J. Am. Chem. Soc. 131, 12540-12541 (2009).

6. Zhang, J. et al. Extra-low-temperature oxygen storage capacity of $\mathrm{CeO}_{2}$ nanocrystals with cubic facets. Nano. Lett. 11, 361-364 (2011).

7. Xia, Y., Xiong, Y., Lim, B. \& Skrabalak, S. E. Shape-controlled synthesis of metal nanocrystals: Simple chemistry meets complex physics? Angew. Chem. Int. Ed. 48, 60-103 (2009).

8. Wei, Z. \& Matsui, H. Rational strategy for shaped nanomaterial synthesis in reverse micelle reactors. Nat. Commun. 5, 3870 (2014).

9. Dulub, O., Diebold, U. \& Kresse, G. Novel stabilization mechanism on polar surfaces: $\mathrm{ZnO}(0001)-\mathrm{Zn}$. Phys. Rev. Lett. 90, 4 (2003).

10. Capdevila-Cortada, M. \& López, N. Entropic contributions enhance polarity compensation for $\mathrm{CeO}_{2}$ (100) surfaces. Nat. Mater. 16, 328-334 (2017).

11. Łodziana, Z., Topsøe, N.-Y. \& Nørskov, J. K. A negative surface energy for alumina. Nat. Mater. 3, 289-293 (2004).

12. Goniakowski, J. \& Noguera, C. Characteristics of Pd deposition on the MgO (111) surface. Phys. Rev. B 60, 16120-16128 (1999).

13. Bliem, R. et al. Subsurface cation vacancy stabilization of the magnetite (001). Surf. Sci. 346, 1215-1218 (2014).

14. Browning, N. D. et al. in Modeling Nanoscale Imaging in Electron Microscopy (eds. Vogt, T., Dahmen, W., \& Binev, P.) 11-40 (Springer, 2012).

15. Senga, R. \& Suenaga, K. Single-atom electron energy loss spectroscopy of light elements. Nat. Commun. 6, 7943 (2015)

16. Su, D. S., Zhang, B. \& Schlögl, R. Electron microscopy of solid catalysts transforming from a challenge to a toolbox. Chem. Rev. 115, 2818-288 (2015).

17. Jinschek, J. R. \& Helveg, S. Image resolution and sensitivity in an environmental transmission electron microscope. Micron 43, 1156-1168 (2012).

18. Jinschek, J. R. Atomic scale structure-function relationship of heterogeneous catalysts: Investigation of gas-solid interactions by ETEM. Microsc. Anal. 26, S5-S10 (2012).

19. Marchetti, A. et al. Understanding surface and interfacial chemistry in functional nanomaterials via solid-state NMR. Adv. Mater. 29, 1605895 (2017).

20. Grey, C. P. \& Dupré, N. NMR studies of cathode materials for lithium-ion rechargeable batteries. Chem. Rev. 104, 4493-4512 (2004).

21. Zheng, A., Li, S., Liu, S.-B. \& Deng, F. Acidic oroperties and structure-activity correlations of solid acid Catalysts revealed by solid-state NMR spectroscopy. Acc. Chem. Res. 49, 655-663 (2016).

22. Bonhomme, C. et al. Advanced solid state NMR techniques for the characterization of sol-gel derived materials. Acc. Chem. Res. 40, 738-746 (2007).

23. Salager, E. et al. Powder crystallography by combined crystal structure prediction and high-resolution ${ }^{1} \mathrm{H}$ solid-state NMR spectroscopy. J. Am. Chem. Soc. 132, 2564-2566 (2010).

24. Deschamps, M. et al. Exploring electrolyte organization in supercapacitor electrodes with solid-state NMR. Nat. Mater. 12, 351-358 (2013).

25. Kong, $\mathrm{X}$. et al. Mapping of functional groups in metal-organic frameworks. Science 341, 882-885 (2013).

26. Peng, Y.-K. et al. Trimethylphosphine-assisted surface fingerprinting of metal oxide nanoparticle by ${ }^{31} \mathrm{P}$ solid-state NMR: A zinc oxide case study. J. Am. Chem. Soc. 138, 2225-2234 (2016).

27. Salassa, G. \& Bürgi, T. NMR spectroscopy: a potent tool for studying monolayer-protected metal nanoclusters. Nanoscale Horiz. 3, 457-4463 (2018).

28. Wang, M. et al. Identification of different oxygen species in oxide nanostructures with ${ }^{17} \mathrm{O}$ solid-state NMR spectroscopy. Sci. Adv. 1, e1400133 (2015).

29. Li, Y. et al. Distinguishing faceted oxide nanocrystals with ${ }^{17} \mathrm{O}$ solid-state NMR spectroscopy. Nat. Commun. 8, 581 (2017).

30. Montini, T., Melchionna, M., Monai, M. \& Fornasiero, P. Fundamentals and catalytic applications of $\mathrm{CeO}_{2}$-Based materials. Chem. Rev. 116, 5987-6041 (2016).

31. Vilé, G., Colussi, S., Krumeich, F., Trovarelli, A. \& Pérez-Ramírez, J. Opposite face sensitivity of $\mathrm{CeO}_{2}$ in hydrogenation and oxidation catalysis. Angew. Chem. Int. Ed. 53, 12069-12072 (2014).

32. Chen, A. et al. Structure of the catalytically active copper-ceria interfacial perimeter. Nat. Catal. 2, 334-341 (2019).
33. Fabris, S. et al. Taming multiple valency with density functionals: a case study of defective ceria. Phys. Rev. B 71, 041102 (2005).

34. Hope, M. A. et al. Surface-selective direct ${ }^{17} \mathrm{O}$ DNP NMR of $\mathrm{CeO}_{2}$ nanoparticles. Chem. Commun. 53, 2142-2145 (2017).

35. Ratcliffe, C. I., Ripmeester, J. A. \& Tse, J. S. NMR chemical shifts of dilute ${ }^{1} \mathrm{H}$ in inorganic solids. Chem. Phys. Lett. 120, 427-432 (1985).

36. Gill, L. et al. Fast MAS ${ }^{1} \mathrm{H}$ NMR study of water adsorption and dissociation on the (100) surface of ceria nanocubes: A fully hydroxylated, hydrophobic ceria surface. J. Phys. Chem. C 121, 7450-7465 (2017).

37. Kim, G., Blanc, F., Hu, Y. Y. \& Grey, C. P. Understanding the conduction mechanism of the protonic conductor $\mathrm{CsH}_{2} \mathrm{PO}_{4}$ by solid-state NMR spectroscopy. J. Phys. Chem. C 117, 6504-6515 (2013)

38. Mogilevsky, G., Karwacki, C. J., Peterson, G. W. \& Wagner, G. W. Surface hydroxyl concentration on $\mathrm{Zr}(\mathrm{OH})_{4}$ quantified by ${ }^{1} \mathrm{H}$ MAS NMR. Chem. Phys. Lett. 511, 384-388 (2011).

39. Freude, D. et al. ${ }^{1} \mathrm{H}$ NMR studies on the acidity of zeolites. Chem. Phys. Lett. 128, 62-66 (1986)

40. Medek, A., Harwood, J. S. \& Frydman, L. Multiple-quantum magic- angle spinning NMR: a new method for the study of quadrupolar nuclei in solids. $J$. Am. Chem. Soc. 117, 12779-12787 (1995)

41. Kropp, T., Paier, J. \& Sauer, J. Interactions of water with the (111) and (100) surfaces of ceria. J. Phys. Chem. C 121, 21571-21578 (2017).

42. Pan, Y. et al. Ceria nanocrystals exposing wide (100) facets: Structure and polarity compensation. Adv. Mater. Interfaces 1, 1400404 (2014).

43. Ni, Q. Z. et al. High frequency dynamic nuclear polarization. Acc. Chem. Res. 46, 1933-1941 (2013)

44. Zagdoun, A. et al. Large molecular weight nitroxide biradicals providing efficient dynamic nuclear polarization at temperatures up to $200 \mathrm{~K}$. J. Am. Chem. Soc. 135, 12790-12797 (2013).

45. Halat, D. M. et al. Probing oxide-ion mobility in the mixed ionic-electronic conductor $\mathrm{La}_{2} \mathrm{NiO}_{4+\delta}$ by solid-state ${ }^{17} \mathrm{O}$ MAS NMR spectroscopy. J. Am. Chem. Soc. 138, 11958-11969 (2016).

46. Hung, I. et al. Isotropic high field NMR spectra of Li-ion battery materials with anisotropy >1 MHz. J. Am. Chem. Soc. 134, 1898-1901 (2012)

47. Gao, Y. et al. Morphology-dependent interplay of reduction behaviors, oxygen vacancies and hydroxyl reactivity of $\mathrm{CeO}_{2}$ nanocrystals. Phys. Chem. Chem. Phys. 17, 31862-31871 (2015)

48. Kresse, G. \& Hafner, J. Ab initio molecular-dynamics simulation of the liquidmetal-amorphous-semiconductor transition in germanium. Phys. Rev. B 49, 14251-14269 (1994)

49. Perdew, J. P., Burke, K. \& Ernzerhof, M. Generalized gradient approximation made simple. Phys. Rev. Lett. 77, 3865-3868 (1996).

50. Dudarev, S. L., Botton, G. A., Savrasov, S. Y., Humphreys, C. J. \& Sutton, A. P. Electron-energy-loss spectra and the structural stability of nickel oxide: An LSDA $+U$ study. Phys. Rev. B 57, 1505-1509 (1998).

51. Nolan, M., Parker, S. C. \& Watson, G. W. The electronic structure of oxygen vacancy defects at the low index surfaces of ceria. Surf. Sci. 595, 223-232 (2005).

52. Wu, X.-P. \& Gong, X.-Q. Clustering of oxygen vacancies at $\mathrm{CeO}_{2}(111)$ : critical role of hydroxyls. Phys. Rev. Lett. 116, 086102 (2016).

53. Blöchl, P. E. Projector augmented-wave method. Phys. Rev. B 50, 17953-17979 (1994).

54. Kümmerle, E. A. \& Heger, G. The structures of $\mathrm{C}-\mathrm{Ce}_{2} \mathrm{O}_{3+\delta}, \mathrm{Ce}_{7} \mathrm{O}_{12}$, and $\mathrm{Ce}_{11} \mathrm{O}_{20}$. J. Solid State Chem. 147, 485-500 (1999).

55. Sundholm, D. \& Olsen, J. Finite element multiconfiguration Hartree-Fock calculations on carbon, oxygen, and neon: The nuclear quadrupole moments of ${ }^{11} \mathrm{C},{ }^{17} \mathrm{O}$, and ${ }^{21} \mathrm{Ne}$. J. Phys. Chem. 96, 627-630 (1992).

56. Wu, X.-P. \& Gong, X.-Q. Unique electronic and structural effects in Vanadia/ Ceria-catalyzed reactions. J. Am. Chem. Soc. 137, 13228-13231 (2015).

57. Fronzi, M., Assadi, M. H. N. \& Hanaor, D. A. H. Theoretical insights into the hydrophobicity of low index $\mathrm{CeO}_{2}$ surfaces. Appl. Surf. Sci. 478, 68-74 (2019).

58. Chase, M. W. NIST-JANAF Thermochemical Tables. (American Institute of Physics 1998).

\section{Acknowledgements}

This work was supported by the National Natural Science Foundation of China (NSFC) -Royal Society Joint Program (21661130149) and NSFC (91745202, 21573103, and 21825301). The ECUST group also thanks the Programme of Introducing Talents of Discipline to Universities (B16017) and National Super Computing Centre in Jinan for computing time. L.P. thanks the Royal Society and the Newton Fund for Royal Society Newton Advanced Fellowship. This work was also supported by a Project Funded by the Priority Academic Program Development of Jiangsu Higher Education Institutions. M.A H. would like to thank the Oppenheimer foundation for funding. D.M.H. acknowledges the Cambridge International Trust for funding, and is grateful for support from NECCES, an Energy Frontier Research Center funded by the U.S. Department of Energy, Office of Science, Office of Basic Energy Sciences under Award No. DE-SC0012583. We 
would like to thank Prof. Bingwen Hu. and Dr. Ming Shen in East China Normal University for invaluable discussions and help in this work.

\section{Author contributions}

J.C. and K.Q. carried out the synthesis of ceria nanocubes; J.C., L.S., Y.W. and J.-H.D. carried out XRD, HRTEM, Raman, ICP-MS, N element analyzing, XPS and surface area measurement; J.C., T.L., M.A.H., P.C.M.M.M., L.S., Y.L., X.K. and L.P. performed ${ }^{17} \mathrm{O}$ isotope enrichment, and collected, as well as analyzed the ${ }^{17} \mathrm{O}$ and ${ }^{1} \mathrm{H}$ NMR spectra; J.C., M.A.H., D.M.H. and S.P. collected and analyzed the ${ }^{17} \mathrm{O}$ DNP NMR spectra; X.-P.W. and X.-Q.G. conducted the DFT calculations; J.C., X.-P.W., M.A.H., W.D., C.P.G. and L.P. wrote the manuscript, and all authors discussed the experiments and final manuscript.

\section{Competing interests}

The authors declare no competing interests.

\section{Additional information}

Supplementary information is available for this paper at https://doi.org/10.1038/s41467019-13424-7.

Correspondence and requests for materials should be addressed to X.-P.W., C.P.G. or L.P.
Peer review information Nature Communications thanks the anonymous reviewers for their contribution to the peer review of this work. Peer reviewer reports are available.

Reprints and permission information is available at http://www.nature.com/reprints

Publisher's note Springer Nature remains neutral with regard to jurisdictional claims in published maps and institutional affiliations.

\section{cc) (i)}

Open Access This article is licensed under a Creative Common Attribution 4.0 International License, which permits use, sharing, adaptation, distribution and reproduction in any medium or format, as long as you give appropriate credit to the original author(s) and the source, provide a link to the Creative Commons license, and indicate if changes were made. The images or other third party material in this article are included in the article's Creative Commons license, unles indicated otherwise in a credit line to the material. If material is not included in the article's Creative Commons license and your intended use is not permitted by statutory regulation or exceeds the permitted use, you will need to obtain permission directly from the copyright holder. To view a copy of this license, visit http://creativecommons.org/ licenses/by/4.0/.

(c) The Author(s) 2019 